\title{
Identifying tumor promoting genomic alterations in tumor- associated fibroblasts via retrovirus-insertional mutagenesis
}

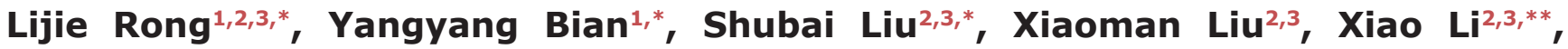 \\ Haiyang Liu ${ }^{2,3,4}$, Jinxue Zhou ${ }^{5}$, Jirun Peng ${ }^{6,7,8}$, Henghui Zhang ${ }^{9}$, Hongsong Chen ${ }^{9}$ \\ and Zhihai Qin ${ }^{1,2,3}$ \\ ${ }^{1}$ Medical Research Center, The First Affiliated Hospital of Zhengzhou University, Zhengzhou University, Zhengzhou, 450052, \\ China \\ ${ }^{2}$ Key Laboratory of Protein and Peptide Pharmaceuticals, Chinese Academy of Sciences-University of Tokyo, Beijing, 100101, \\ China \\ ${ }^{3}$ Joint Laboratory of Structural Virology and Immunology, Institute of Biophysics, Chinese Academy of Sciences, Beijing, \\ 100101, China \\ ${ }^{4}$ University of Chinese Academy of Sciences, Beijing, 100049, China \\ ${ }^{5}$ Henan Tumor Hospital, Zhengzhou, 450008, China \\ ${ }^{6}$ Department of Surgery, Beijing Shijitan Hospital, Capital Medical University, Beijing, 100038, China \\ ${ }^{7}$ Capital Medical University Clinical Cancer Center, Beijing, 100038, China \\ ${ }^{8}$ Ninth Clinical Medical College of Peking University, Beijing, 100038, China \\ ${ }^{9}$ Peking University People's Hospital, Peking University Hepatology Institute, Beijing, 100044, China \\ *These authors have contributed equally to this work \\ *** Current Address: Beijing Institute For Drug Control, Beijing, 102206, China \\ Correspondence to: Zhihai Qin, email: zhihai@ibp.ac.cn \\ Keywords: Tumor-associated fibroblasts, retrovirus-insertional mutagenesis, tumor-promoting gene, co-injection model, THI \\ Received: July 04, $2017 \quad$ Accepted: September 21, $2017 \quad$ Published: October 16, 2017 \\ Copyright: Rong et al. This is an open-access article distributed under the terms of the Creative Commons Attribution License 3.0 \\ (CC BY 3.0), which permits unrestricted use, distribution, and reproduction in any medium, provided the original author and source \\ are credited.
}

\section{ABSTRACT}

Tumor-associated fibroblasts (TAFs) are often essential for solid tumor growth. However, few genetic or epigenetic alterations have been found in TAFs during the progression of solid tumors. Employing a tumor-stromal cell co-injection model, we adapted here retroviral-insertional mutagenesis to stromal cells to identify novel tumorassociated genes in TAFs. We successfully identified 20 gene candidates that might modulate tumor growth if altered in TAFs at genomic level. To validate our finding, the function of one of the candidate genes, tubulin tyrosine ligase (TtI), was further studied in TAFs from fibrosarcoma, colon, breast and hepatocarcinoma. We demonstrated that down-regulated TTL expression in TAFs indeed promoted tumor growth in mice. Interestingly, decreased expression of $T T L$ in tumor stromal cells also correlated with poor outcome in human colon carcinoma. Thus, the co-injection model of tumor cells with retrovirus-modified fibroblasts proved a valid method to identify tumor-modulating genes in TAFs, allowing for a deeper insight into the role of the stroma for tumor development.

\section{INTRODUCTION}

Spontaneous genetic or epigenetic aberrations are hallmarks of tumor cells, but are also discovered in some stromal cells $[1,2]$. Heterozygosity is often lost in stromal cells that surround tumor cells in human epithelial tumor tissues [3-6]. Some studies argue for rare genetic aberrations in stromal cells [7] that might originate from tumor cells after epithelial-mesenchymal transition [8]. It is widely acknowledged that co-evolution with tumor cells favors genetically or epigenetically abnormal tumor stromal cells $[1,9]$. Most aberrations were found in fibroblast-like 
stromal cells, also known as tumor-associated fibroblasts (TAFs). Altered genes including Pten[10], Tgfbr2[11], Tp53[3], Sqstm1[12], Ereg[13], Ifngr[14], Hifla and Vegfa[15] were identified from genetically engineered mice that limit a technically complicated and time-consuming attempt to only one gene per strain. Using artificial tumor microenvironments, gene expression profiling of fibroblasts co-cultured with tumor cells [16], or growth factor induced TAFs [17], also revealed altered genes in TAFs that functionally associated with tumor growth, such as IDH $3 \alpha[17]$. We here aim for a strategy that systematically identifies multiple functional tumor-associated genes in TAFs from dynamic tumor progression in vivo.

Retroviral genomes naturally insert into a cell genome during phylogenesis and ontogenesis [18] where it can activate oncogenes or inactivate tumor-associated genes [19]. The so called retrovirus-insertional mutagenesis has been widely applied to screen tumor-associated genes in tumor cells [19-22]. The tumor-stromal cell co-injection model helped to identify functions of tumor-associated genes in TAFs in vivo, for the convenience of genetically manipulating TAFs without altering the tumor cells themselves $[23,24]$. Our previous study demonstrated that mouse embryonic fibroblasts (MEFs) upon co-injection mainly differentiated into TAFs [14], making MEFs suitable for this system [14, 20, 23, 25-27]. Combining the advantages of retrovirus-insertional mutagenesis to produce shotgun-mutated MEF libraries and co-injecting them with different tumor cell types into mice, we established a new method to identify multiple functional tumorassociated genes in TAFs. This strategy effectively models complex tumor-stroma interaction in vivo. We successfully discovered 20 tumor-associated candidate genes and subsequently confirmed $T t l$, the gene for tubulin tyrosine ligase as tumor-suppressor gene in TAFs within different mouse tumor models. Strikingly, low TTL expression in tissues of human colon cancer or hepatocarcinoma correlated with poor prognosis. These results demonstrate the power of our new strategy to identify relevant tumorassociated genes in TAFs.

\section{RESULTS}

\section{Establishment of the co-injection model of tumor cells with a fibroblast library containing shotgun gene mutations}

We hypothesized that during in-vivo tumor progression from co-injected tumor cells and a pool of MEFs mutated by retroviral insertion that we call retroMEFs, only the subsets of retro-MEFs with tumorpromoting potential survive, proliferate and enrich in the tumor stroma. The retroviral integration sites in the genome DNA of this retro-MEF progeny, further called TA-MEFs and considered equivalent to TAFs, can be identified and will provide the information on tumor- associated genes within the tumor stroma. We first tested the feasibility of all steps of our strategy.

To estimate the infection efficiency and ensure ample numbers of retro-MEFs for use in the mouse model, we infected freshly prepared MEFs with retrovirus produced by a packaging cell line $293 \mathrm{~T}$ that was transfected with the pMIG-LT vector (Figure 1A and $1 \mathrm{C}$ ). After 72 hours, about $30 \%$ of the retro-MEFs were $\mathrm{GFP}^{+}$(Figure 1B) and retrovirus-specific LTR amplicons from MEFs' genomic DNA demonstrated successful integration (Figure 1C). In our previous study, the proportion of $\mathrm{GFP}^{+}$TAFs in the tumor established by the co-injection of $\mathrm{GFP}^{+} \mathrm{MEFs}$ with tumor cells became less than $2 \%$ after 16 days [14]. So, it was technically challenging to purify these $\mathrm{GFP}^{+}$MEFs. We tested a pLPC-TERT retrovirus containing a puromycin-resistance gene (Figure 1A) and found it successfully integrating into the genome of infected MEFs too (Figure 1C). These MEFs were easily enriched by puromycin selection that effectively eliminated e.g. contaminating tumor cells or host fibroblasts. We next investigated the capacity of retroMEFs to support tumor development. If co-injected with FB61 fibrosarcoma cells, MEFs infected with pMIG-LT or pLPC-TERT retrovirus, equally supported FB61 tumor growth (Figure 1D). Therefore, the pLPC-TERT retrovirus was used in the following study.

Addressing cell-dose dependencies and specificity in the co-injection model, we started with FB61 cells in combination with non-mutated MEFs. Tumors were successfully established after subcutaneous injection of MEFs $\left(1 \times 10^{5}\right)$ combined with low numbers of FB61 cells $\left(2 \times 10^{4}\right)$, while MEFs or FB61 cells alone did not establish tumors (Figure 2A). We further co-injected FB61 cells with parental retro-MEFs or TA-MEFs, and injected very large numbers of TA-MEFs $\left(5 \times 10^{6}\right)$ alone to test their tumorigenicity (Figure 2B). Tumor-derived TA-MEFs were not only superior to retro-MEFs or normal MEFs in supporting tumor development (Figure 2C), but dosedependently augmented tumor growth (Figure 2D). During TA-MEF purification from tumor tissues, the efficiency of puromycin selection was routinely assessed by parallel in-vitro culture of FB61 tumor cells in the presence of puromycin (see Supplementary Figure 1). To ensure absent tumor cell contamination in the TA-MEF preparations, the selective pressure of puromycin was kept in the TAMEFs cultures for an additional week. Final TA-MEFs preparations did not contain cells with the hematopoietic or endothelial cell markers CD45 and CD31 (not shown). All cells expressed the mesenchymal cell markers vimentin, $\alpha$-smooth muscle actin (SMA), fibroblastspecific protein (FSP)-1 and ER-TR7 (Figure 2E). The staining result is consistent with our previous finding that the progeny of MEFs in such co-injection models mostly displayed an appearance of fibroblasts. Our experimental setup did not exclude that a small proportion of coinjected MEFs might have differentiated into other cell 
types [14]. Since these were not tumor cells, we assumed them negligible for the overall effects. The products of LAM-PCR from retro-MEFs out of FB61 and TS/A tumor tissues appear as continuum of amplicon length, whereas a decreased diversity of retroviral integration sites in the TA-MEFs is represented by defined bands with very high intensity against a reduced background of amplicon length (Figure 2F-2G).

Taken together, TA-MEFs were able to support substantial tumor growth with $2 \times 10^{4}$ co-injected tumor cells, an amount that was used in all following experiments. Fulfilling a prerequisite condition for our screening strategy, selective enrichment of limited numbers of LTR-containing amplicons during tumor progression indicated that the TA-MEFs derived from retro-MEFs indeed functioned as TAFs.

\section{Identification of retrovirus integration sites}

Twelve batches of TA-MEFs re-isolated from coinjection models with FB61 (6/12), TS/A (4/12) and MCA205 (2/12) were subjected to LAM-PCR. For each batch, the three most abundant bands were cloned and sequenced. We obtained sequence data from 68/144 colonies from the FB61-tumor model whereas 55 of them contained LAM-PCR adaptor and retroviral LTR sequences. DNA sequences between LAM adaptor and retroviral LTR were compared to mouse genomic DNA sequences, 16/55 showed similarities higher than 95\%. These numbers suggested valid amplification of TAF genomic DNA adjacent to the insertion site and successful identification of retrovirus insertion sites. Increasing the confidence in the identified integration sites, only sites located within, or up/down-stream of a gene within a window size of $30 \mathrm{~kb}$ were considered further. Finally, the FB61 model revealed 7 different insertion sites while an altered Ttl gene was found twice. Using the same screening strategy, we identified 5 and 2 additional insertion sites from the TS/A and MCA-205 model, respectively.

Totally, our co-injection strategy identified 20 tumorassociated candidate genes from TAFs that located in 14 retroviral insertion sites (Table 1). We reanalyzed four published GSE datasets (GEO: GSE40595, GSE38666, GSE45001, GSE26910) [28-32] from the NCBI GEO database that focused on gene expression differences between tumor stroma and normal stroma, using the online shinyGEO tool [33] (http://bioinformatics.easternct. edu/shinyGEO/). Underlining the high relevance of our identified gene candidates for tumor development, 16/20 genes including $T t l$ were found significantly altered (Table 2, detailed information in Supplementary Table 1).

The location of retrovirus integration suggests the direction of regulation of the candidate genes. Four gene candidates (Ttl, Hist1h4m, Slc43a2, Stab1) inserted
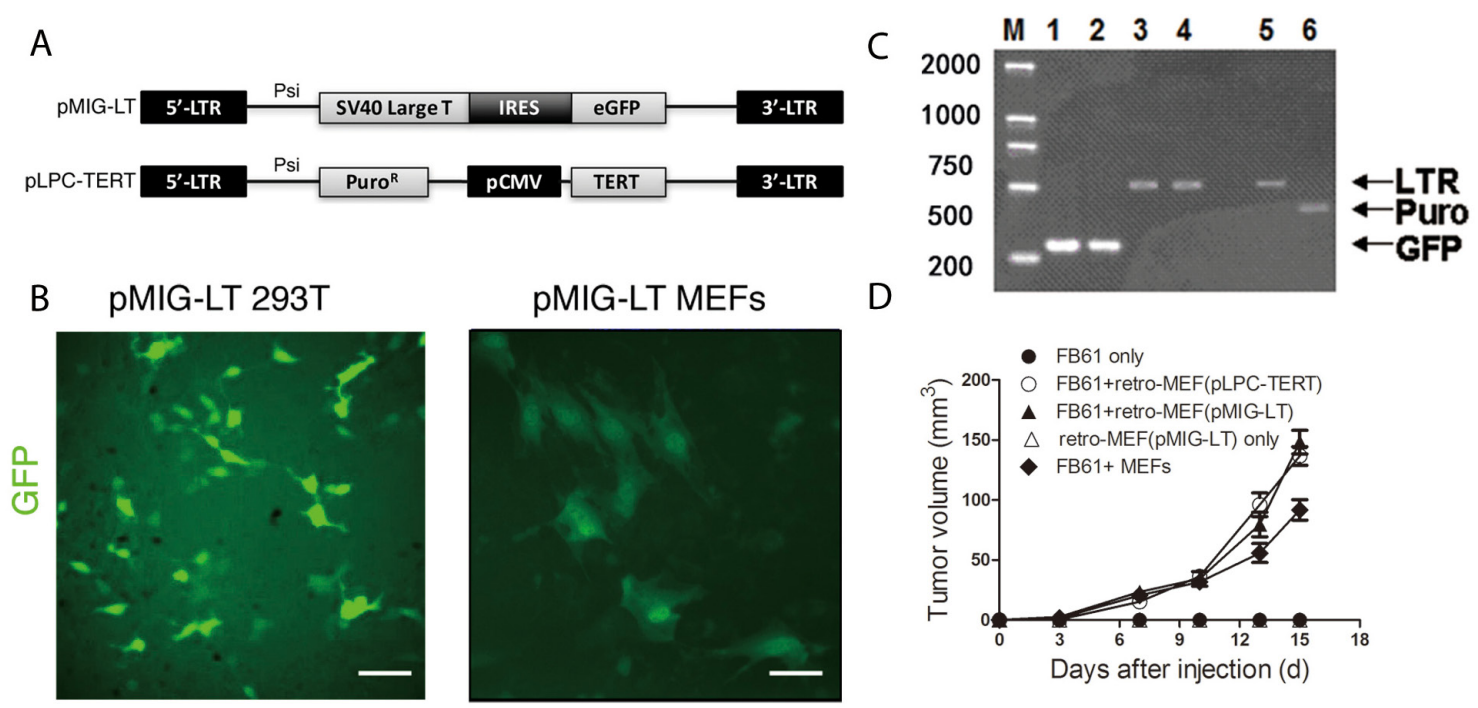

Figure 1: Production of a fibroblast library with shotgun gene mutations (retro-MEFs). (A) Schema of the retroviral insertion sequences from the plasmids pMIG-LT and pLPC-TERT. (B) 293T cells (left panel) and freshly prepared MEFs (right panel) were transfected with pMIG-LT and cultured on slide for $24 \mathrm{~h}$. Green fluorescence was assessed by fluorescence microscopy. Scale bars, $50 \mu \mathrm{m}$; data are representative of two independent experiments. (C) Agarose-gel images showing successful transfection. pMIG-LT was used to transfect 293T cells (lanes 1,3) or MEFs (lane 2,4); pLPC-TERT for MEFs (lanes 5,6). Inserted retroviral sequences were assessed by RT-PCR specific for GFP (amplicon size: 278 bp; lanes 1-2), retroviral LTR (amplicon size: 512 bp; lanes 3,4,5) or the puromycinresistance gene (amplicon size: $441 \mathrm{bp}$; lane 6). M, marker. (D) Retro-MEFs were prepared by infecting MEFs with pMIG-LT (LT-GFP) or pLPC-TERT (TERT-puro) retrovirus. FB61 tumor cells were injected alone or in combination with retro-MEFs as indicated. Injection of retro-MEFs with pMIG-LT retroviral particles served as control. Tumor volumes were monitored over time as indicated. Mean $\pm \mathrm{SEM}$, ${ }^{* *} P<0.01$, two-way ANOVA, $\mathrm{n}=4$ per group; data are representative of two independent experiments. 
in an exon with putative loss-of-function. Asking for the biological relevance of our findings in TAFs, we focused the following study on the functional role of $\mathrm{Ttl}$ that encodes an enzyme catalyzing posttranslational tyrosination of $\alpha$-tubulin [34]. Lafanechere et al. showed a tumor-suppressor role for Ttl in NIH-3T3 fibroblasts [35], but considered these cell solely as tumor cells. Their study does not reflect on $T t l$ as a tumor-suppressor gene from the non-tumorous cell compartment within the tumor microenvironment as we specifically do here [14].

\section{$T t l$ is a tumor suppressor gene in stromal cells during tumor progression}

We next studied the tumor-suppressing capacity of $T t l$ in TAFs. The retrovirus insertion site within the exon 4 of $T t l$ indicated suppression of the $T t l$ expression (Figure 3A). Indeed, Ttl mRNA levels of TA-MEFs from the FB61 model were significantly lower compared with parental retro-MEFs (Figure 3B) - a finding repeated in TA-MEFs from most FC34, CT26 tumors and one TS/A tumor (Figure 3C-3E). To exclude extraneous effects of fibroblasts, host TAFs from $\mathrm{H} 22$ and J558L tumors without MEFs co-injection were isolated. In H22 TAFs, $T t l$-mRNA levels were lower than that in normal dermal fibroblasts (Figure 3F). Notably, Ttl was not suppressed in the majority of the TA-MEFs from the TS/A tumors (Figure 3E) or J558L host TAFs (Figure 3G).

To investigate whether TAFs with reduced $T t l$ expression favor tumor growth, we suppressed $T t l$ expression exclusively in MEFs by anti-Ttl shRNA (TTL ${ }^{\text {low }}$ MEFs) before co-injection (Figure 4A-4C). Very low doses of TTL ${ }^{\text {low }}$ MEFs generated by shTtl-1 significantly promoted the in vivo growth of FB61, TS/A, CT26 and H22 tumors (Figure 4D-4G). A similar phenomenon was observed if ten times larger numbers of FB61 tumor cells were co-injected at the same ratio with $\mathrm{TTL}^{\text {low }} \mathrm{MEFs}$ transduced with shTtl-2. We concluded that the effect on tumor growth of TTL ${ }^{\text {low }}$ MEFs neither depended on the inactivating $T t l$ sequence nor on the tumor cell number (Figure 4H). We hypothesized that tumor-promoting gene alterations increase proliferation of TAFs enabling them to enrich in a tumor. Indeed, TTL ${ }^{\text {low }}$ MEFs proliferated stronger than control MEFs in vitro (Figure 4I) and the $\alpha-\mathrm{SMA}^{+}$proportion in vivo in CT26 tumors containing TTL $^{\text {low }}$ MEFs was moderately increased (Figure 4J). Taken
A

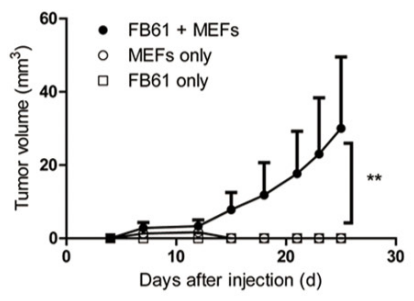

D

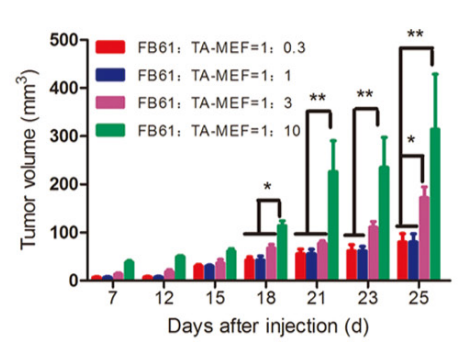

B

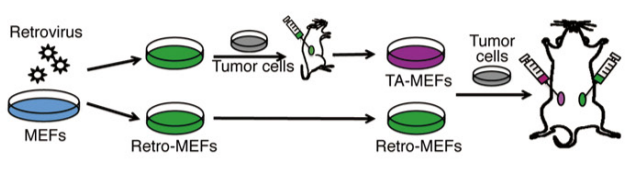

C

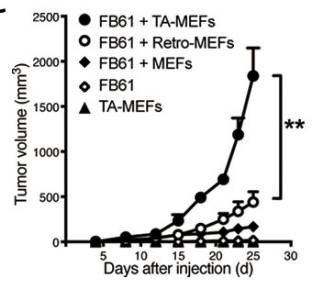

E
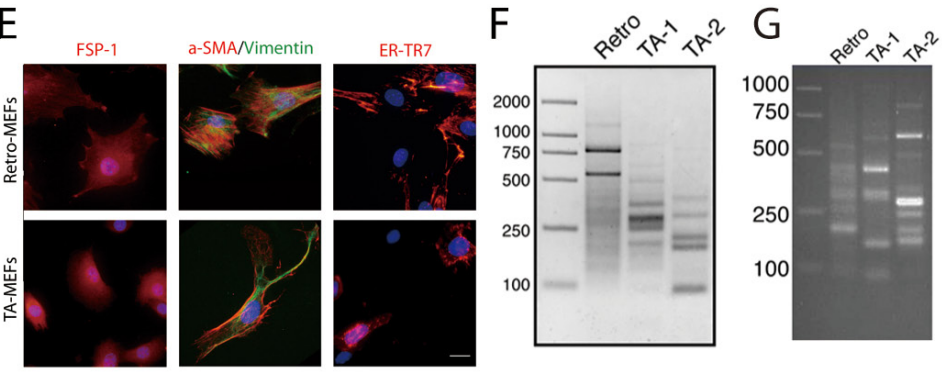

Figure 2: In vivo discovery of tumor-associated genes in TA-MEFs. (A) BALB/c mice were subcutaneously injected with MEFs in combination with FB61 tumor cells. Injection of FB61 tumor cells or MEFs alone served as control. Tumor volumes were monitored over time as indicated. Mean $\pm \mathrm{SEM},{ }^{* *} P<0.01$, two-way ANOVA, $\mathrm{n}=6$ per group; data are representative of three independent experiments. (B) Schema for the functional development of TA-MEFs from shotgun transduced MEFs (retro-MEFs) via primary tumor passage. (C) BALB/c mice were subcutaneously injected with MEFs, retro-MEFs or TA-MEFs in combination with FB61 tumor cells. Injection of FB61 tumor cells or larger number of TA-MEFs $\left(5 \times 10^{6}\right)$ alone served as control. Tumor volumes were monitored over time as indicated. Mean \pm SEM, ${ }^{* *} P<0.01$, two-way ANOVA, $\mathrm{n}=6$ per group; data are representative of three independent experiments. (D) FB61 cells were mixed with TA-MEFs at different ratios as indicated before co-injection into BALB/c mice. Tumor volumes were monitored over time as indicated. Mean $\pm \mathrm{SEM},{ }^{*} P<0.05,{ }^{* *} P<0.01$, two-way ANOVA, $\mathrm{n}=5$ per group; data are representative of two independent experiments. (E) TA-MEFs isolated from tumors established by co-injection of retro-MEFs and FB61 tumor cells were stained for FSP-1, $\alpha$-SMA/vimentin or ER-TR7 and assessed by confocal microscopy. Nuclei were counterstained with DAPI. Scale bars, $20 \mu \mathrm{m}$; data are representative of two independent experiments. (F, G) LAM-PCR was performed for retro-MEFs and TA-MEFs isolated from FB61 (F) and TS/A (G) tumors. TA-1 and TA-2 were two different batches of TA-MEFs isolated from two different tumors. Data are representative of three independent experiments. 
Table 1: Summary of retroviral insertion sites in the genome and tumor-associated candidate genes in TAFs from three mouse tumor models

\begin{tabular}{|c|c|c|c|c|c|}
\hline Tumor model & Insertion ID & Symbol & $\begin{array}{l}\text { Subclones } \\
\text { identified }\end{array}$ & $\begin{array}{l}\text { Retroviral } \\
\text { insertion }\end{array}$ & Summary of function \\
\hline \multirow{9}{*}{ FB-61 } & FB-1 & $T t l$ & 2 & Exon 4 & $\begin{array}{l}\text { Post-translational } \\
\text { tyrosination of } \\
\text { the detyrosinated } \\
\alpha \text {-tubulin }\end{array}$ \\
\hline & FB-2 & Hist $1 \mathrm{~h} 4 \mathrm{~m}$ & 4 & Exon 1 & $\begin{array}{l}\text { Transcription } \\
\text { regulation }\end{array}$ \\
\hline & FB-3 & Coro $2 b$ & 2 & Intron 7 & $\begin{array}{l}\text { Binds to F-actin and } \\
\text { to vinculin }\end{array}$ \\
\hline & FB-4 & Slc43a2 & 1 & Exon 7 & $\begin{array}{l}\text { Large neutral amino } \\
\text { acids transportation }\end{array}$ \\
\hline & FB-5 & Fcho2 & 2 & Intron 1 & $\begin{array}{l}\text { Imposing and } \\
\text { stabilizing particular } \\
\text { membrane curvatures }\end{array}$ \\
\hline & FB-6 & Cct3 & 4 & $19.9 \mathrm{~kb}$ up & Chaperonin \\
\hline & FB-6 & $R h b g$ & 4 & $22.8 \mathrm{~kb}$ up & $\begin{array}{l}\text { Ammonium } \\
\text { transporter }\end{array}$ \\
\hline & FB-7 & $Z f x$ & 1 & $28.9 \mathrm{~kb}$ up & $\begin{array}{l}\text { Potential } \\
\text { transcriptional } \\
\text { activator }\end{array}$ \\
\hline & M-1 & $B m x$ & 2 & $11.8 \mathrm{~kb}$ up & $\begin{array}{l}\text { Intracellular signaling } \\
\text { cascade }\end{array}$ \\
\hline \multirow[t]{6}{*}{ MCA-205 } & M-1 & Pir & 2 & Intron 1 & NFI/CTF1 cofactor \\
\hline & M-2 & $\operatorname{Tex} 13$ & 2 & $24.2 \mathrm{~kb}$ up & Unknown \\
\hline & TS-1 & Stat3 & 1 & $0.5 \mathrm{~kb}$ up & $\begin{array}{l}\text { STAT transcription } \\
\text { factor }\end{array}$ \\
\hline & TS-2 & Stabl & 5 & Exon 6 & Scavenger receptor \\
\hline & TS-3 & $A b t 1$ & 2 & $8.2 \mathrm{~kb}$ up & $\begin{array}{l}\text { Transcription co- } \\
\text { activator }\end{array}$ \\
\hline & TS-3 & Btnlal & 2 & $29.2 \mathrm{~kb}$ down & $\begin{array}{l}\text { Functions in the } \\
\text { secretion of milk-fat } \\
\text { droplets }\end{array}$ \\
\hline \multirow[t]{5}{*}{$\mathrm{TS} / \mathrm{A}$} & TS-4 & S100a2 & 4 & $2.0 \mathrm{~kb}$ down & $\begin{array}{l}\text { Ca2+-binding S100 } \\
\text { protein }\end{array}$ \\
\hline & $\mathrm{TS}-4$ & S100a3 & 4 & $7.9 \mathrm{~kb}$ up & $\begin{array}{l}\text { Ca2+-binding } \mathrm{S} 100 \\
\text { protein }\end{array}$ \\
\hline & TS-4 & S100a4 & 4 & $11.5 \mathrm{~kb}$ up & $\begin{array}{l}\text { Ca2+-binding S100 } \\
\text { protein(Fibroblast } \\
\text { specific protein) }\end{array}$ \\
\hline & TS-5 & Hnrpl & 2 & $21.2 \mathrm{~kb}$ up & $\begin{array}{l}\text { Nucleic acid and } \\
\text { nucleotide binding }\end{array}$ \\
\hline & TS-5 & $N f k b i b$ & 2 & $22.2 \mathrm{~kb}$ up & NF-kappa B inhibitor \\
\hline
\end{tabular}


Table 2: Appearance of tumor-associated candidate genes from TAFs identified in this study in published datasets comparing tumor stroma (TAF) and normal stroma (NF) from human tissues

\begin{tabular}{lcccc}
\hline Symbol & GSE accessions & FC $=$ TAF/NF & p-value & Tissue type \\
\hline PIR & GSE26910 & 0.45 & 0.003 & Breast \\
S100A4 & GSE26910 & 0.33 & 0.002 & Prostate \\
SLC43A2 & GSE38666 & 4.00 & 0.009 & Ovary \\
S100A2 & GSE38666 & 20.00 & $<0.001$ & Ovary \\
STAB1 & GSE38666 & 9.09 & $<0.001$ & Ovary \\
S100A4 & GSE38666 & 8.33 & 0.001 & Ovary \\
TTL & GSE40595 & 0.26 & $<0.001$ & Ovary \\
S100A4 & GSE40595 & 9.55 & $<0.001$ & Ovary \\
CCT3 & GSE40595 & 9.61 & $<0.001$ & Ovary \\
FCHO2 & GSE40595 & 2.49 & 0.003 & Ovary \\
STAT3 & GSE40595 & 5.43 & $<0.001$ & Ovary \\
S100A2 & GSE40595 & 3.94 & $<0.001$ & Ovary \\
STAB1 & GSE40595 & 4.47 & $<0.001$ & Ovary \\
BMX & GSE45001 & 0.15 & $<0.001$ & Bile duct \\
S100A3 & GSE45001 & 9.34 & $<0.001$ & Bile duct \\
S100A2 & GSE45001 & 4.88 & 0.003 & Bile duct \\
\hline
\end{tabular}

*Genes with fold change (FC) values $>2.0$ or $<0.5$ and $\mathrm{p}<0.01$ were considered significantly up- or down-regulated.

together, these results pointed to tumor-type dependent $T t l$ suppression in TAFs that might be sufficient to promote the growth of certain tumor types independent of TAF proliferation.

\section{Low TTL expression correlates with poor prognosis of human tumors}

To investigate whether TTL is relevant in human tumors besides neuroblastoma [36], we examined TTL expression levels in human colon carcinoma and hepatocarcinoma tissues. In colon, TTL was highly expressed in the non-glandular stromal cells of nonmalignant areas, but drastically decreased in the TAF-like stromal cells within tumor areas (Figure 5A). A similar phenotype was observed in inflammation induced mouse colon tumors (AOM/DSS, Figure 5B). Detyrosinated $\alpha$-tubulin was accumulated in stromal cells of human hepatocarcinoma tissues, indicating a TTL ${ }^{\text {low-like }}$ phenotype (Figure 5C). Underlining this, TTL-mRNA levels in colon tumor tissues were significantly lower than that in non-malignant colon tissues (Figure 5D). To evaluate the clinical significance of TTL, patients with colon tumors were grouped into TTL ${ }^{\text {high }}$ and TTL $^{\text {low }}$ based on the relative TTL mRNA-levels within the tumor. Eighty months post-surgery, patients in the TTL ${ }^{\text {high }}$ group showed better overall survival compared to the TTL ${ }^{\text {low }}$ group (Figure 5E), and multivariate survival analysis showed that such grouping based on TTL levels significantly impacted survival of patients (Supplementary Table 2). Although TTL levels did not correlate with size or metastasis of colon tumors (Supplementary Table 3), the average TTL levels in T4-stage tumor tissues was significantly lower than that in T3 stage (Figure 5F). Similarly, low TTL levels were also associated with shorter survival times of hepatocarcinoma patients (Figure 5G). However, due to the limited samples, the multivariate survival analysis here did not show such grouping significantly impacted the survival of patients, just as parameters like age, tumor stage and size as well as the degree of liver fibrosis (Supplementary Table 4). Together, the results indicated that low TTL levels in human tumors might be a novel indicator of poor prognosis.

\section{DISCUSSION}

More and more studies demonstrated that tumor stroma, especially TAFs are essential in tumor progression. We here for the first time, applied retrovirus insertional mutagenesis to MEFs (TAF precursors) and used them in an in vivo tumor-stroma co-injection model to identify tumor-associated genes in TAFs. This strategy successfully 
identified 20 putative tumor-associated candidate genes in TAFs; some were previously reported as tumor-associated in TAFs, such as Stat3[37], Stab1 [38], and Nfkbib[39]. We deliberately choose $\mathrm{Ttl}$ to underline the biological relevance of the findings using this method and validated the tumorpromoting ability of $\mathrm{Ttl}$ in TAFs. Differential expression of other candidate genes like Pir and Bmx between tumor stroma and normal stroma [28-31], indicated the power of the method to address TAFs functions.

Taking in account that the number of processed retroviral insertion sites was relatively limited, we here used a strategy based on cloned LAM-PCR amplicons

A

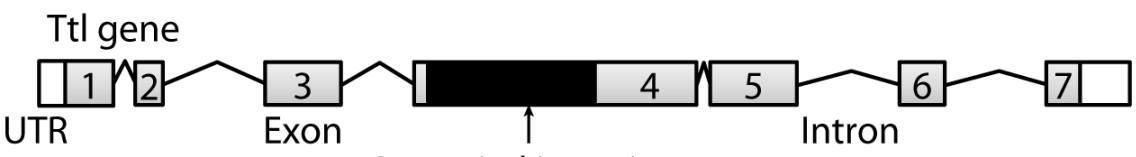

Retroviral insertion

B

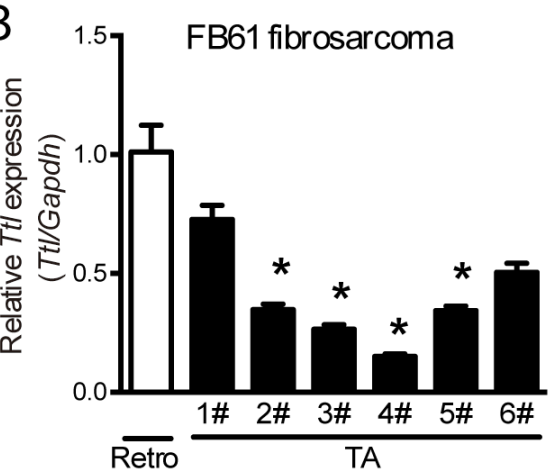

D

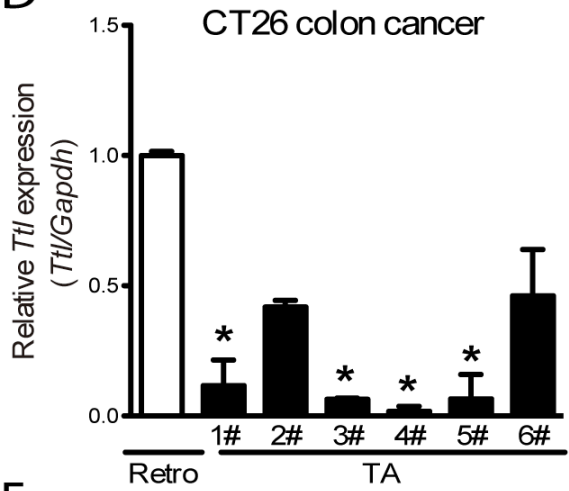

F

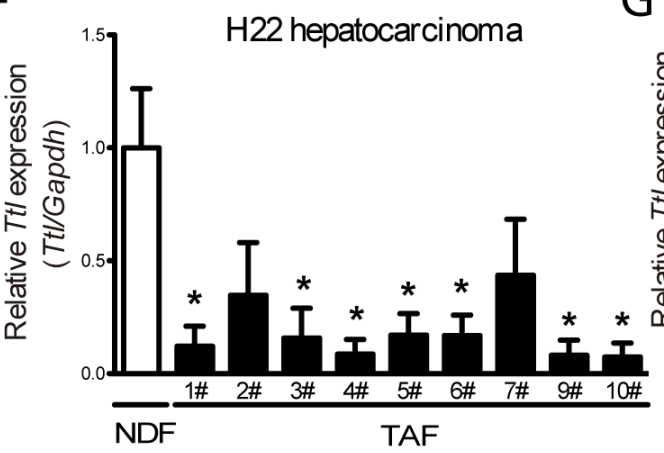

C

E
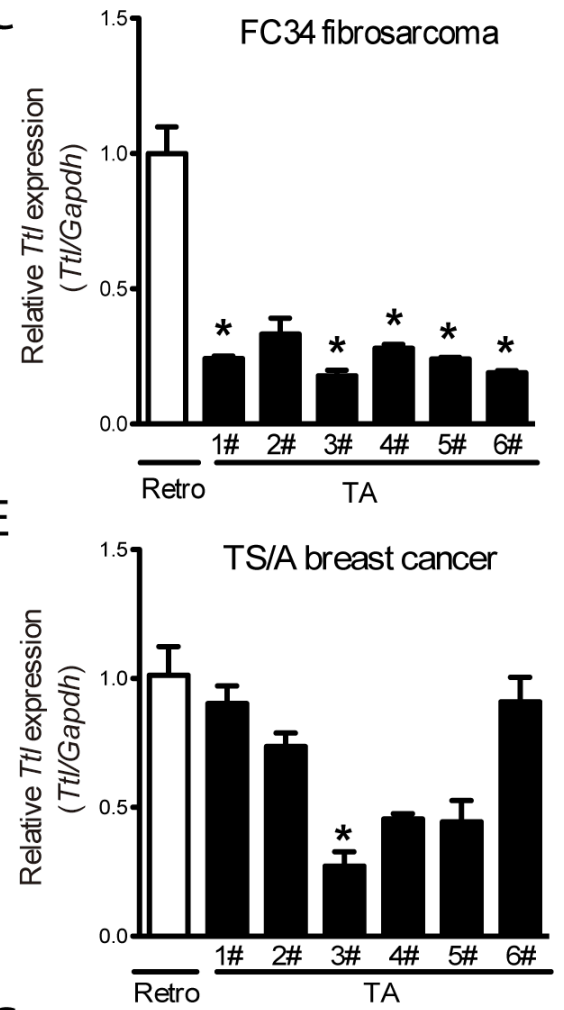

G

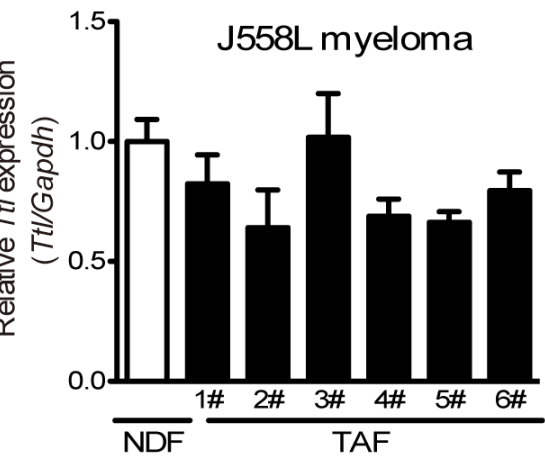

Figure 3: Suppressed stromal $\boldsymbol{T} t \mathbf{l}$ expression in different mouse tumor models. (A) Schema of the retroviral integration site in the Ttl gene. Grey boxes with numbers represent the exons. Lines represent introns. Black boxes indicate the inserted retroviral genome. White boxes indicate untranslated regions (UTR). (B-E) Ttl mRNA levels in retro-MEFs and TA-MEFs (TA) isolated from (B) FB61, (C) FC34, (D) CT26, or (E) TS/A tumors. (F-G) Ttl mRNA levels in normal dermal fibroblasts (NDFs) and tumor-associated fibroblasts (TAFs) isolated from the subcutaneously transplanted (F) H22, n=10, and (G) J558L tumors, $n=6$. (B-G) Each bar indicates RT-PCR replicates of one batch of stromal cells re-isolated from a distinct tumor. Mean $\pm \mathrm{SEM},{ }^{*} P<0.05$, Student's $t$ test, $\mathrm{n}=6$ per model; data are representative of two independent experiments. 
[40]. This approach enabled the identification of insertion sites that were most abundant in the TAF population, and, as we assumed, the most likely to be functional in TAFs for tumor growth. Confirming known functional tumorassociated genes in stromal cells such as Stat3[37] and the proof that the found altered $T t l$ indeed is another tumor- suppressor gene in TAFs supports the strength of this assumption. Of course, this selective approach has some drawbacks. It misses less-enriched insertions and does not allow statistical analysis among the candidate genes or between different tumor models. These questions can be addressed in further studies by deep sequencing.
A

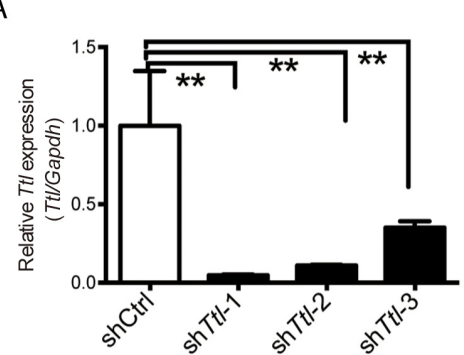

B

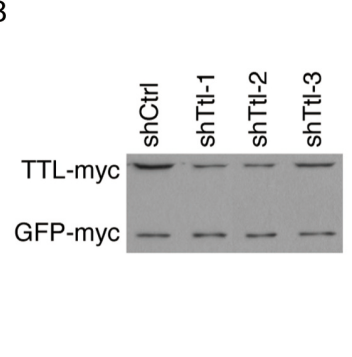

C

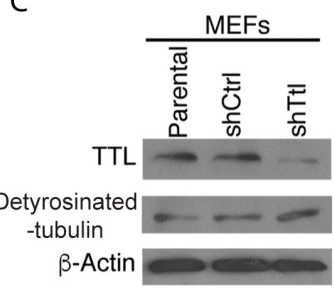

D

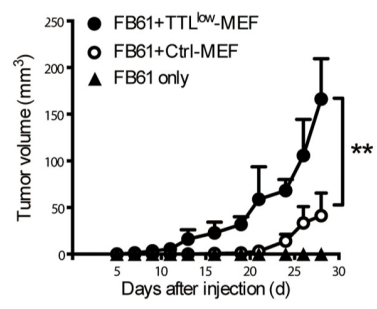

E

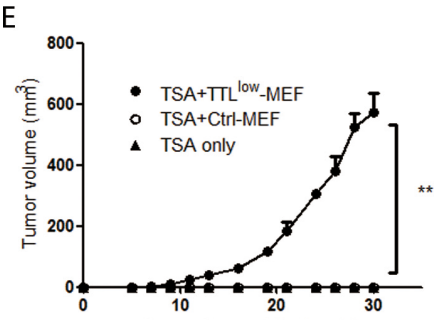

Days after co-injection (d)
$\mathrm{F}{ }^{1500} \longrightarrow \bullet \mathrm{CT} 26+$ TLL Low MEFs

O CT26+CtrI MEFs

- CT26only

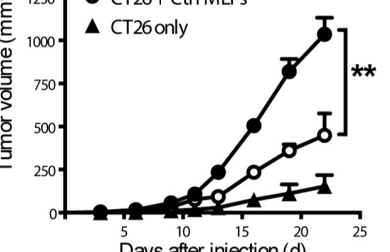

5 ays after injection (d)
Dat

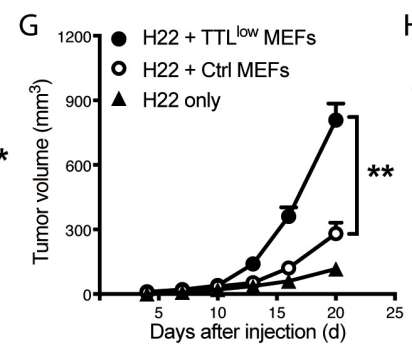

$\mathrm{H}$

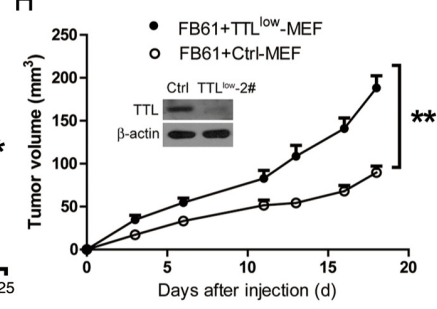

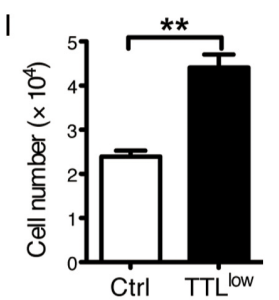
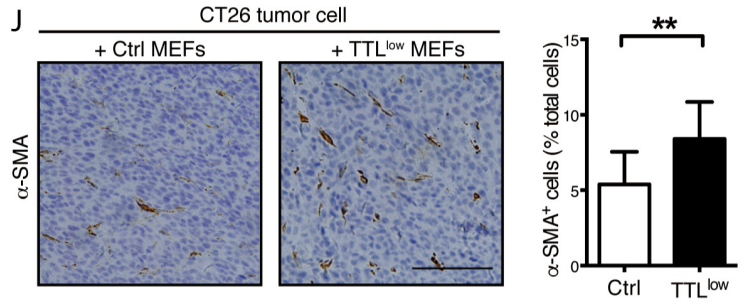

Figure 4: Promoted tumor growth by suppressed stromal $\mathbf{T t}$ expression. (A-C) Knock-down of Ttl in MEFs by three shTtl sequences. Three shTtl sequences were cloned into pSUPER.retro.puro plasmid. The 293T cells were transfected with either shTtl or non-targeting shCtrl vectors, together with a plasmid that carries murine $T t l$ and GFP cDNA with independent myc-tags for the expression of murine Ttl in the 293T cells, which is human origin. The efficacy of shTtl was determined after 24 hours. (A) Real time RT-PCR. Mean \pm SEM, ${ }^{* *} P<0.01$, Student's $t$ test, $n=3$ RT-PCR replicates; data are representative of two independent experiments. (B) Western-blot analysis using an antibody specific for the myc-tag to show TTL-myc ( 45 $\mathrm{kDa})$ in comparison to GFP-myc $(\sim 27 \mathrm{kDa})$ as control for transfection efficiency. Data are representative of two independent experiments. (C) MEFs were transduced with shTtl-1 (shTtl) or shCtrl retroviral particles. Western-blot analysis using antibodies specific to TTL $(\sim 45 \mathrm{kDa})$ and detyrosinated $\alpha$-tubulin (detyrosinated-tubulin; $\sim 50 \mathrm{kDa})$. $\beta$-actin $(\sim 42 \mathrm{kDa})$ served as loading control. Data are representative of three independent experiments. (D-G) TTL ${ }^{\text {low }}$ MEFs (transduced with shTtl-1) or Ctrl MEFs were co-injected with $2 \times 10^{4}$ (D) FB61, (E) TS/A, (F) CT26, or (G) H22 tumor cells. As a control, $2 \times 10^{4}$ tumor cells were injected alone. Tumor volumes were monitored over time as indicated. Mean $\pm \mathrm{SEM},{ }^{* *} P<0.01$, two-way ANOVA, $\mathrm{n}=6$ per group; data are representative of two of three independent experiments. (H) $1 \times 10^{6} \mathrm{TTL}^{\text {low }} \mathrm{MEFs}$ (transduced with shTtl-2) or control MEFs were co-injected with $2 \times 10^{5}$ FB61 tumor cells. Tumor volumes were monitored over time. Mean \pm SEM, ${ }^{*} P<0.05$, two-way ANOVA, $\mathrm{n}=3$; data are representative of two independent experiments. Insert: Western-blot analysis for $T t l$ and $\beta$-actin in MEFs transduced with shTtl-2 as described for Figure 4C. (I) Aormazan-based assay were used for cell proliferation analysis of TTL ${ }^{\text {low }}$ MEFs or control MEFs. Mean $\pm \mathrm{SEM},{ }^{* *} P<0.01$, Student's $t$-test, $\mathrm{n}=6$ culture replicates; data are representative of three independent experiments. (J) CT26 tumor cells were co-injected into mice with either TTL ${ }^{\text {low }}$ or control MEFs. Tumor sections were stained with $\alpha$-SMA (brown). (Left) Representative images for the staining are shown. Scale bar, $50 \mu \mathrm{m}$. (Right) The proportion of $\alpha-\mathrm{SMA}^{+}$cells in the total cells was calculated (counted with nuclear numbers) from 5-6 visual fields (35 visual fields in total) of 3 sections of each tumor. Mean $\pm \mathrm{SEM},{ }^{* *} P<0.01$, Student's $t$-test, n=6 tumors per group; data are representative of three independent experiments. 
So far, abnormal $T t l$ expression in the epithelial component of tumors is much better studied than in stromal cells [35, 36, 41-45]. Germline deletion of $\mathrm{Ttl}$ gene results in perinatal death of mouse [44]. High frequencies $(20 \%)$ of $T T L$ alterations has been found in prostate adenocarcinoma [46]. Ttl loss-of-function occurs in different tumor cells, and correlates with tumor progression [35, 36, 41-45]. Most of these tumor cells are the epithelial component of tumor, and only a few studies made mention of varied $T t l$ expression in the stromal components of a tumor, especially in TAFs [41]. Even if $T t l$ levels assessed at mRNA level from whole tumor tissues acceptably substantiates the prognostic value of TTL expression in human tumor tissues, our study suggests

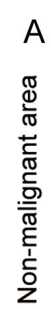$$
\text { ্ֻৰ }
$$
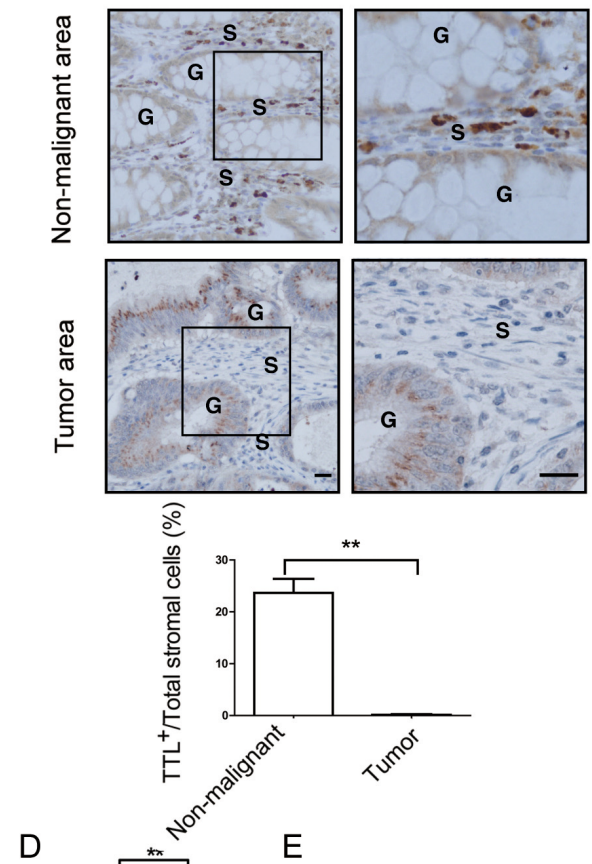

B
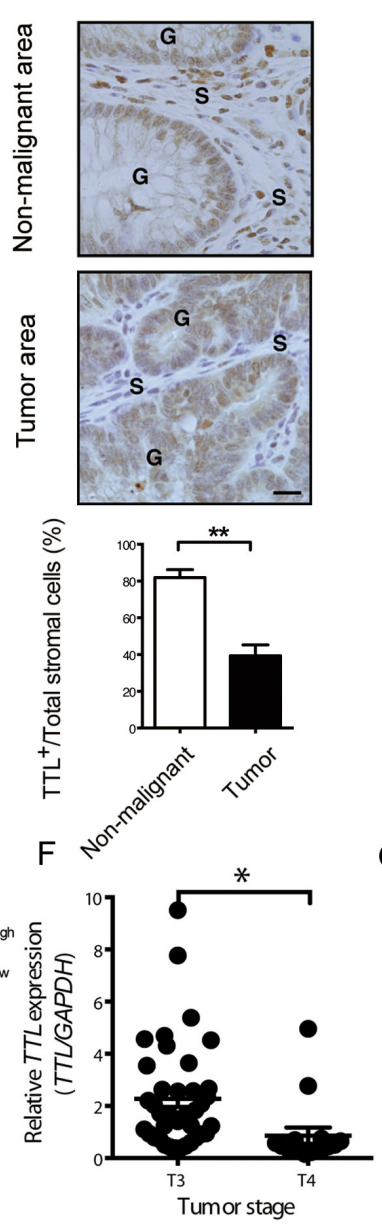
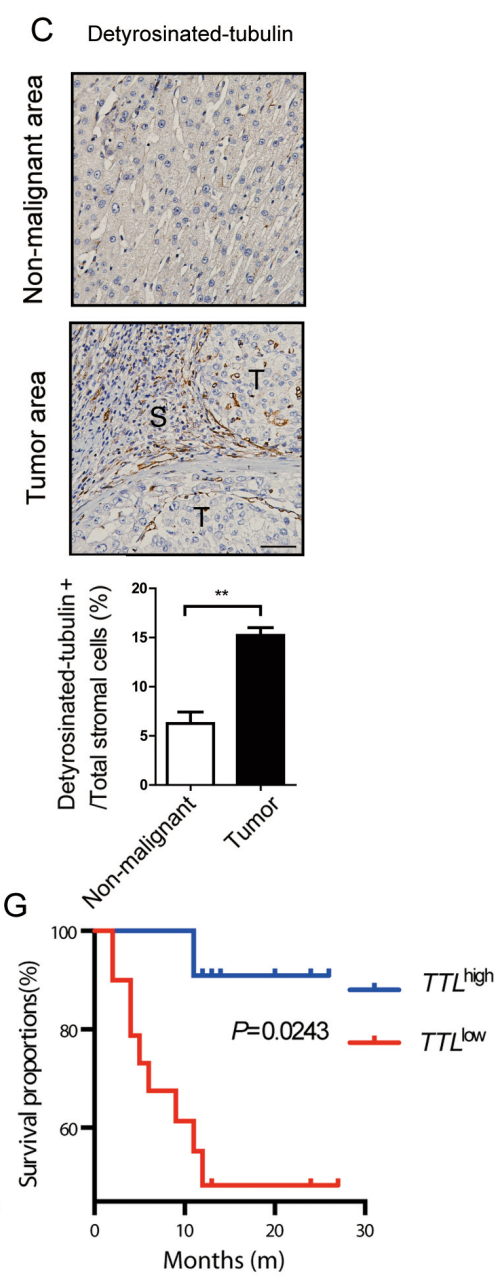

Figure 5: Suppressed TTL expression in stromal cells of human colon and liver cancer tissues. (A) Paraffin-embedded tissue samples $\pm 1 \mathrm{~cm}$ from the boundary of a tumor nodule (tumor area) or more than $2 \mathrm{~cm}$ away from tumor nodules (non-malignant areas) of human colon carcinoma were stained by immunohistochemistry for TTL (brown). (Upper left panel) Representative images from colon areas of one patient; boxed areas enlarged next to original (upper right panel); G, colonic glands; S, stroma; scale bars, $20 \mu \mathrm{m}$. (B) Representative images of $\mathrm{TTL}^{+}$cells (brown) stained in non-malignant and adenoma areas of the colon tissues from a mouse model of intestinal inflammation-induced carcinogenesis (AOM/DSS). G, colonic glands; S, stromal surrounding the colonic glands; scale bars, $20 \mu \mathrm{m}$. (C) Tumor and non-tumor areas as described in (A) from human hepatocarcinoma tissues were stained for detyrosinated-tubulin (abbreviated as "Glu-tublin", brown). Representative images from liver tissue areas from one patient. T, tumor nests; S, stroma. Bars, 50 $\mu \mathrm{m}$. (A-C, lower panels) Proportions of TTL or detyrosinated-tubulin stromal cells were calculated by counting $\mathrm{TTL}^{+}$or detyrosinatedtubulin ${ }^{+}$stromal cells and all nuclei within the stroma from 35 visual fields (AOM/DSS induced), or 6 visual fields (human colon or liver) tissue sample. Mean \pm SEM, ${ }^{* *} P<0.01$, Student's $t$ test, $\mathrm{n}=6$ tumors per group. (D) Human TTL mRNA levels in non-malignant colon tissues $(\mathrm{n}=72)$ and colon tumor tissues $(\mathrm{n}=77)$. Scatter plot and mean, ${ }^{* * *} P<0.0001$, Student's $t$ test. Cut-off value for definition of TTL high samples set as 2.0. (E) TTL ${ }^{\text {low }}$ and TTL high expression in colon tumor tissue was correlated to the overall survival of the colon tumor patients after surgery. $P<0.01, \log$-rank test, $\mathrm{n}=72$. (F) The TTL expression levels in colon tumor tissues from T3 $(\mathrm{n}=42)$ and T4 stage $(\mathrm{n}=16)$ were compared. Scatter plot and mean, ${ }^{*} P=0.012$, Student's $t$ test. (G) TTL ${ }^{\text {low }}$ and TTL high expression in liver tumor tissues was defined as described in (D) and correlated to the overall survival times of the hepatocarcinoma patients after surgery. $P=0.0243, \log$-rank test, $\mathrm{n}=31$. 
that it is much more accurate to address it at protein level in stromal compartment e.g. by immunohistochemistry for TTL or detyrosinated tubulin.

Lafanechere et al. elegantly investigated Ttl suppression in NIH-3T3 fibroblasts using these fibroblasts as tumor cells [35], while we explicitly focused on the function of $T t l$ in tumor stromal cells. Knock-down of $T t l$ promoted the proliferation of MEFs in in-vitro culture. However, in our new in vivo model of co-injecting tumor cells and retro-MEFs, promoted tumor growth was not mainly due to the increased TAF numbers or proliferation. Last but not least, injection of only small numbers of tumor cell $\left(2 \times 10^{4}\right)$ or MEFs alone did not establish tumor in mice. At these cell doses, the mixture of both tumor cells and MEFs was required. All this is in line with our previous work with normal MEFs where arresting proliferation by gamma-radiation did not affect the tumorpromoting capacity of MEFs in vivo, in a similar tumorstroma co-injection model [14]. Therefore, we concluded that promoting TAF proliferation in general is only a minor factor for tumor growth.

Having demonstrated Ttl to be a "driver" gene of the tumor-promoting capacity of TAFs, we cannot fully exclude that our strategy identifies proliferation-related genes without tumor-associated function, so called "passenger" genes. Thus, subsequent functional validation of the candidate gene from TAFs during tumor progression is mandatory to confirm its "driver" gene function, as exemplified by $T t l$ here. Notably, with Ttl, S100a4, Zfx, Cct3, Stat3, Stab1 and Bmx, 7/20 found candidate genes have been reported as proliferation-related in tumor cells too $[27,35,47-53]$. We hypothesize that tumor-promoting gene alterations supporting TAFs proliferation and segregation within the tumor stroma enabled the enrichment of these TAFs and made them accessible. The current retrovirus-insertional mutagenesis is limited by non-random integration and low efficiency. We anticipate that less biased mutation systems such as the Sleeping Beauty transposon will improve the sensitivity of our model.

\section{MATERIALS AND METHODS}

\section{Patient samples and ethics}

Archived formaldehyde-fixed, paraffin-embedded and frozen tumor tissue were obtained the Peking University People's Hospital and Henan Tumor Hospital samples. Tumor tissue was defined within these samples by the tumor nodules and areas $\pm 1 \mathrm{~cm}$ from the boundary of a tumor nodule. Non-malignant colon tissue was defined from the same samples as areas more than $2 \mathrm{~cm}$ distant from any tumor nodule. Fresh colon tissues from surgery that used for RNA preparation were from 77 colon cancer patients, as well as from 72 age- and sexmatched non-tumor patients of the Henan Tumor Hospital. Fresh surgical liver tissues from 31 hepatocarcinoma cancer patients were obtained from the Peking University People's Hospital. Protocols concerning clinical sample use were approved by the Ethics Committee of Henan Tumor Hospital or Peking University People's Hospital. Protocols concerning animal use were approved by the Institution of the Animal Care and Use Committee of Institute of Biophysics, Chinese Academy of Sciences (SYXK2013-36).

\section{Mouse strains, MEFs and tumor cell lines}

$\mathrm{BALB} / \mathrm{c}$ and $\mathrm{C} 57 \mathrm{BL} / 6$ mice were purchased from Vital River (China). Age matched (6-8 weeks) female mice were used in all experiments and randomly allocated to experimental and control groups. MEFs were prepared from E13.5 mouse embryos as described [14]. The following cell lines were used: $293 \mathrm{~T}$ human embryonic kidney, CT26 undifferentiated colon carcinoma (ATCC, LGC Standards), FB61 and FC34 fibrosarcoma (BALB/c) [54], MCA-205 fibrosarcoma (C57BL/6)[55], TS/A mammary adenocarcinoma $[56,57]$ and $\mathrm{J558 \textrm {L } \text { myeloma }}$ $[56,57]$. H22 mouse hepatocarcinoma cells were kindly provided by Dr. Yingxin Xu (The General Hospital of People's Liberation Army, Beijing, China). If not noted otherwise, cell lines were of murine origin. Cells were cultured in DMEM (293T, CT26) or RPMI 1640 medium supplemented with $10 \%$ newborn calf serum and $100 \mathrm{IU} /$ $\mathrm{mL}$ penicillin/streptomycin (all from Gibco).

\section{Plasmids}

The pMIG-LT plasmid contained the a green fluorescent protein (GFP) and SV40 large-T fragment from LoxP-HyTK-SV40Tag [58] subcloned to the pMIG vector [59]. Vectors for expressing myc-tagged murine $T t l$ or GFP based on pcDNA4-myc (Invitrogen) were kindly provided by Dr. Guangxia Gao (Institute of Biophysics, Chinese Academy of Sciences, Beijing, China). Oligonucleotides specific for mouse $T t l$ and non-targeting sequences were cloned into pSUPER.retro.puro (Oligo Engine) to produce shTtl-retroviral particles.

\section{Retrovirus production and transfection}

The 293T cells were transfected with pMIG-LT or pLPC-TERT (Clontech) (Figure 1A) in combination with the pCL-10A1 packaging vector (Imgenex). MEFs were repeatedly infected with freshly prepared retrovirus-containing cell-culture supernatant [60]. We later refered to these cells as retro-MEFs. The 293T cells were transfected with the retroviral vectors pMIG-LT, pLPC-TERT (Clontech) or pSUPER.retro.puro-based shTtl/Ctrl in combination with the $\mathrm{pCL}-10 \mathrm{~A} 1$ packaging vector (Imgenex) using Lipofectamine 2000 (Invitrogen). After 48 and 72 hours of culture, supernatants were collected, filtered (pore size: $0.45 \mu \mathrm{m}$; Millipore) and used immediately. To construct retro-MEFs, retrovirus- 
containing $293 \mathrm{~T}$ supernatant was mixed with equal volumes of fresh culture medium, supplemented with 8 $\mu \mathrm{g} / \mathrm{mL}$ polybrene (Sigma-Aldrich) and added to $3 \times 10^{5}$ MEFs in a 6-well plate The plate was spun at $1,500 \times \mathrm{g}$ and $31^{\circ} \mathrm{C}$ for 1 hour. After 6 hours at $37^{\circ} \mathrm{C}$, medium was replaced for fresh culture medium. Increasing the infection efficiency, the whole procedure was repeated three times [60].

To knock-down $\mathrm{Ttl}$ expression in MEFs or in $293 \mathrm{~T}$ cells co-transfected to express myc-tagged murine $\mathrm{Ttl}$ and myc-tagged GFP, $1 \mathrm{~mL}$ retrovirus-containing $293 \mathrm{~T}$ supernatant supplemented with $4 \mu \mathrm{g} / \mathrm{mL}$ polybrene was added to $2 \times 10^{4}$ MEFs or $293 \mathrm{~T}$ cells. Cells were incubated at $37{ }^{\circ} \mathrm{C}$ for 12 hours before the medium was replaced for fresh culture medium. At 36 hours post infection, cells were collected to determine mouse Ttl expression. The following sequences specific for the mouse $T t l$ gene and a non-targeting control sequence were synthesized:

shTtl-1, 5'-gCATTCAgAAAGAgTACTC-3';

shTtl-2, 5'-ggCAACgTTTggATTgCAA-3'; shTtl-3: 5'-AgTATAATATCTACCTCTA-3'; shCtrl: 5'-AAgCTgACCCTgAAg-3'.

\section{Tumor transplantation}

Exponentially growing tumor cells from standard culture were harvested, washed twice with PBS and subcutaneously injected into the abdominal region of the mice. In the co-injection model, mice received $2 \times 10^{4}$ tumor cells and $1 \times 10^{5}$ retro-MEFs (passages $3-6$ ). Tumor volumes were measured and calculated by (length $\times$ width $\times$ width) $/ 2$ over time.

\section{Isolation of tumor stromal cells and fibroblasts}

Sixteen days after co-injecting tumor cells and retroMEFs, tumors were surgically removed, cut into small fragments about $3 \times 3 \times 3 \mathrm{~mm}$ and digested with $0.48 \mathrm{U} / \mathrm{mL}$ collagenase NB4 (Serva) for $30 \mathrm{~min}$ at $37^{\circ} \mathrm{C}$. Single-cell suspensions were cultured in fibroblast medium consisting of DMEM supplemented with $10 \%$ newborn calf serum and $3 \mu \mathrm{g} / \mathrm{mL}$ puromycin. After $<14$ days in vitro, genomic DNA was extracted. Retro-MEFs subjected to the same in-vitro selection procedure served as controls. J558L and $\mathrm{H} 22$ tumor cells $\left(1 \times 10^{5}\right)$ were injected into mice as described above. Twenty days later, cells from the tumors were isolated, cultured in fibroblast medium before suspension-tumor cells were removed by washing the cell layers with fresh fibroblast medium the following day. The remaining adherent TAFs were passaged and identified by immunostaining for the fibroblasts markers $\alpha$-smooth muscle actin (SMA) and ER-TR7. Normal dermal fibroblasts were isolated from mice with the same genetic background as the host mice of TAFs, as described before [61].

\section{Linear amplification-mediated (LAM)-PCR}

LAM-PCR was performed as described earlier [40]. Briefly, genomic DNA from TA-MEFs was digested with the NlaIII restriction enzyme and subsequently amplified using a biotinylated primer LTRI (BT-LTRI, 5'-BiogTTCgCTTCTCgCTTCTgTTCgC-3'). Amplification products were purified with streptavidin-coated Dynabeads M-280 (Invitrogen) and ligated to a linker cassette. Nonbiotinylated strands denatured by $\mathrm{NaOH}(100 \mathrm{mM})$ served as templates for the subsequent nested PCR with the following primers:

LTRII: 5'-CTCAATAAAAgAgCCCACAACCC CT-3';

LTRIII: 5'-ACTTgTggTCTCgCTgTTCCTTg-3'

LAM-PCR Products were separated on $2 \%$ agarose gels and purified using MiniElute columns (Qiagen). For each sample, 3 most clearly and brightly enriched gel bands were purified and sub-cloned into the pMD19-T vector (Takara). E. coli TOP10 (Invitrogen) were transformed with the resulting plasmids. Plasmids were purified and sequenced using the M13 primer sites. Sequences adjacent to retroviral long terminal repeats (LTR) were blasted against the mouse genome (NCBI) [40]. The sequences of cloning primers were as follows:

Forward: 5'-CCggAAgATCTgCCACCATggATAA AgTTTTAAACAgAg-3';

Reverse: 5'-ggATCCggAATTCTTATgTTTCAggT TCAggg-3'.

All oligonucleotides used within this study were purchased from Sangon Biotech (Shanghai, China).

\section{Real-time RT-PCR}

Total RNA from $1 \times 10^{6}$ murine fibroblasts or from clinical samples was extracted using TRIzol reagent (Invitrogen) and $2 \mu \mathrm{g}$ RNA was reversely transcribed by M-MLV reverse transcriptase (Promega). Expression levels of $\mathrm{Ttl}$ were determined in relation to glyceraldehyde3-phosphate dehydrogenase (Gapdh) using the iQTM SYBR Green Supermix on MyiQTM system (Bio-Rad). The specific primers for real-time PCR were:

\section{Western-blot analysis}

Cells were lysed by RIPA solution before proteins were separated and transferred to nitrocellulose membrane (GE Healthcare) as described before [54]. Briefly, cells were lysed by RIPA solution (50 mM Tris- $\mathrm{HCl}$ [pH 7.5], $150 \mathrm{mM} \mathrm{NaCl}, 1.0 \%$ Nonidet P-40, $0.5 \%$ sodium deoxycholate, $0.1 \%$ sodium dodecyl sulfate, $1 \mathrm{mM}$ EDTA) supplemented with $100 \mu \mathrm{M}$ phenylmethanesulfonyl fluoride, $25 \mu \mathrm{g} / \mathrm{mL}$ aprotinin, 1 $\mathrm{mM}$ sodium orthovanadate, and $50 \mathrm{mM} \mathrm{NaF}$ [54]. Proteins from cell extracts were separated using homogenous 10\% SDS-PAGE and transferred to a nitrocellulose membrane 


\begin{tabular}{|c|c|c|}
\hline \multirow[t]{2}{*}{ Mouse } & $T t l$ & $\begin{array}{l}\text { Sense: 5'-TgTAgACCATgTAgTTgAggT-3' } \\
\text { Anti-sense: 5'-TACgACTCggggAACCATgAg-3' }\end{array}$ \\
\hline & Gapdh & $\begin{array}{l}\text { Sense: 5'-AggTCggTgTgAACggATTTg-3' } \\
\text { Anti-sense: 5'-TgTAgACCATgTAgTTgAggT-3' }\end{array}$ \\
\hline \multirow[t]{2}{*}{ Human } & $T T L$ & $\begin{array}{l}\text { Sense: 5'-CAgCTCTTCggCTTTgACTT-3' } \\
\text { Anti-sense: 5'-GCTgTgggCTggATAAAgAg-3' }\end{array}$ \\
\hline & GAPDH & $\begin{array}{l}\text { Sense: 5'-AAgAAggTggTgAAgCAggC-3' } \\
\text { Anti-sense: 5'-TCCACCACCCTgTTgCTgTA-3' }\end{array}$ \\
\hline
\end{tabular}

(GE Healthcare) on a semi-dry transfer device (Bio-Rad). Binding of mouse-specific primary antibodies for TTL (1:2,000, SAB1103321, Sigma-Aldrich), $\beta$-actin (1:8,000, a5441, Sigma-Aldrich), rabbit polyclonal detyrosinated $\alpha$-tubulin (1:2,000, ab3201, Millipore), and myc tag (1,000 clone 9E10, Thermo) were visualized using peroxidaseconjugated secondary antibodies (Thermo). The following peroxidase-conjugated secondary antibodies were used: goat anti-rabbit $(1: 15,000,32460$, Thermo $)$ and goat antimouse $(1: 10,000,31430$, Thermo). Membranes were incubated with a chemiluminescent substrate (Thermo) for 5 minutes and exposed to X-ray film (Kodak).

\section{Proliferation assay}

The cell proliferation was determined using the Cell Counting Kit-8 (Sigma-Aldrich) according to the manufacturers' instructions. In brief, MEFs were plated in a 96-well plate with the density of $2 \times 10^{4}$ cells/well, and cultured for 68 hours before the addition of CCK8 solution. To each well, $10 \mu \mathrm{L}$ CCK-8 solution were added and cells were cultured for additional 4 hours. The absorbance of the water soluble formazan product was measured at a wavelength of $450 \mathrm{~nm}$ using a microplate reader (Bio-rad).

\section{Immunofluorescent staining and immunohistochemistry}

Cells $\left(8 \times 10^{3}\right)$ were seeded on $10 \times 10 \mathrm{~mm}$ coverslips and cultured for 12 hours before staining. Primary antibodies included: rat anti-mouse ER-TR7 (ab51824, Abcam); rabbit anti-mouse CD31 (ab28364, Abcam), vimentin (ab45939, Abcam), FSP-1 (ab27957, Abcam) and CD45 (550539, BD Biosciences); and mouse monoclonal antibody $\alpha$-SMA (ab5694, Abcam). Secondary antibodies were conjugated with Alexa Fluor 555 or Alexa Fluor 488 (Invitrogen) and nuclei counterstained with 4',6-diamidino-2-phenylindole (Sigma-Aldrich). Slides were assessed by confocal microscopy (FV1000) and images analyzed using the FV10-ASW1.7 Viewer software (both Olympus). Paraffin sections of mouse or human tissues were stained with rabbit anti-mouse TTL (SAB1103321, Sigma-Aldrich) or detyrosinated $\alpha$-tubulin (ab3201, Millipore) using diaminobenzidine histochemistry kits (Invitrogen). Slides were assessed by brightfield microscopy (DP71, Olympus) and images analyzed using the Image-Pro Plus software (Media Cybernetics).

\section{Statistical analysis}

All data are from two to three independent experiments. Statistical analysis was performed using the GraphPad Prism software (GraphPad). P-values $<0.05$ were considered statistically significant.

\section{CONCLUSION}

For the first time, we successfully established a method to identify tumor-associated genes in TAFs in vivo by applying retrovirus insertional mutagenesis to MEFs in a tumor-stroma co-injection model. TA-MEFs reisolated from tumors after co-injection exhibit augmented tumor-promoting capacity. Exemplified by suppressed $T t l$ expression, we show new evidence supporting the hypothesis that TAFs containing tumor-promoting genetic/epigenetic changes are selected in the tumor microenvironment. Taken together, we provide a proof of concept how insertional mutagenesis can be used as a novel strategy to identify tumor-associated genes in TAFs.

\section{Abbreviations}

$\alpha$-SMA: $\alpha$-smooth muscle actin; GAPDH: glyceraldehyde-3-phosphate dehydrogenase; GFP: greenfluorescent protein; LAM-PCR: linear amplificationmediated PCR; LTR: long terminal repeat; MEF: mouse embryonic fibroblast; TAF: tumor-associated fibroblast; TA-MEF: tumor-associated MEF; TERT: telomerase reverse transcriptase; $T t l$ : tubulin tyrosine ligase;

\section{Author contributions}

Zhihai Qin, Lijie Rong, and Shubai Liu designed experiments; Lijie Rong, Shubai Liu, Xiaoman Liu, Xiao Li, Haiyang Liu, Jinxue Zhou, Jirun Peng, Henghui Zhang, and Hongsong Chen performed experiments; Lijie Rong, Yangyang Bian, and Shubai Liu analyzed data; Lijie 
Rong, Yangyang Bian, Shubai Liu, and Zhihai Qin wrote the paper. All authors read and approved the final version of the manuscript.

\section{ACKNOWLEDGMENTS}

The authors thank Dr. Ulrike Erben for comments and improvements of the manuscript, and Dr. Shu Xing for providing AOM/DSS-induced mouse colon adenoma sections.

\section{CONFLICTS OF INTEREST}

The authors declare no conflicts of interest.

\section{FUNDING}

This work was supported by the National Natural Science Foundation of China [81630068, 31670881, $81600046, \quad 81030049, \quad 31071261,81001328$ and 81261130024].

\section{REFERENCES}

1. Hu M, Yao J, Cai L, Bachman KE, van den Brule F, Velculescu V, Polyak K. Distinct epigenetic changes in the stromal cells of breast cancers. Nat Genet. 2005; 37: 899-905.

2. Eng C, Leone G, Orloff MS, Ostrowski MC. Genomic alterations in tumor stroma. Cancer Res. 2009; 69: 6759-64.

3. Hill R, Song Y, Cardiff RD, Van Dyke T. Selective evolution of stromal mesenchyme with p53 loss in response to epithelial tumorigenesis. Cell. 2005; 123: 1001-11.

4. Kurose K, Gilley K, Matsumoto S, Watson PH, Zhou XP, Eng C. Frequent somatic mutations in PTEN and TP53 are mutually exclusive in the stroma of breast carcinomas. Nat Genet. 2002; 32: 355-7.

5. Patocs A, Zhang L, Xu Y, Weber F, Caldes T, Mutter GL, Platzer P, Eng C. Breast-cancer stromal cells with TP53 mutations and nodal metastases. N Engl J Med. 2007; 357; 2543-51.

6. Ashida S, Orloff MS, Bebek G, Zhang L, Zheng P, Peehl DM, Eng C. Integrated analysis reveals critical genomic regions in prostate tumor microenvironment associated with clinicopathologic phenotypes. Clin Cancer Res. 2012; 18: 1578-87.

7. Qiu W, Hu M, Sridhar A, Opeskin K, Fox S, Shipitsin M, Trivett M, Thompson ER, Ramakrishna M, Gorringe KL, Polyak K, Haviv I, Campbell IG. No evidence of clonal somatic genetic alterations in cancer-associated fibroblasts from human breast and ovarian carcinomas. Nat Genet. 2008; 40: 650-5.

8. Shipitsin M, Campbell LL, Argani P, Werernowicz S, Bloushtain-Qimron N, Yao J, Nikolskaya T, Serebryiskaya T, Beroukhim R, Hu M, Halushka MK, Sukumar S, Parker
LM, et al. Molecular definition of breast tumor heterogeneity. Cancer Cell. 2007; 11: 259-73.

9. Polyak K, Haviv I, Campbell IG. Co-evolution of tumor cells and their microenvironment. Trends Genet. 2009; 25: 30-8.

10. Trimboli AJ, Cantemir-Stone CZ, Li F, Wallace JA, Merchant A, Creasap N, Thompson JC, Caserta E, Wang H, Chong JL. Pten in stromal fibroblasts suppresses mammary epithelial tumours. Nature. 2009; 461: 1084-91.

11. Bhowmick NA, Chytil A, Plieth D, Gorska AE, Dumont N, Shappell S, Washington MK, Neilson EG, Moses HL. TGF-beta signaling in fibroblasts modulates the oncogenic potential of adjacent epithelia. Science. 2004; 303: 848-51.

12. Valencia T, Kim JY, Abu-Baker S, Moscat-Pardos J, Ahn CS, Reina-Campos M, Duran A, Castilla EA, Metallo CM, DiazMeco MT, Moscat J. Metabolic reprogramming of stromal fibroblasts through p62-mTORC1 signaling promotes inflammation and tumorigenesis. Cancer Cell. 2014; 26: 121-35.

13. Neufert C, Becker C, Tureci O, Waldner MJ, Backert I, Floh K, Atreya I, Leppkes M, Jefremow A, Vieth M, SchneiderStock R, Klinger P, Greten FR, et al. Tumor fibroblastderived epiregulin promotes growth of colitis-associated neoplasms through ERK. J Clin Invest. 2013; 123: 1428-43.

14. Lu Y, Yang W, Qin C, Zhang L, Deng J, Liu S, Qin Z. Responsiveness of stromal fibroblasts to IFN-gamma blocks tumor growth via angiostasis. J Immunol. 2009; 183: 6413-21.

15. Kim JW, Evans C, Weidemann A, Takeda N, Lee YS, Stockmann C, Branco-Price C, Brandberg F, Leone G, Ostrowski MC, Johnson RS. Loss of fibroblast HIF-1alpha accelerates tumorigenesis. Cancer Res. 2012; 72: 3187-95.

16. Fromigue O, Louis K, Dayem M, Milanini J, Pages G, Tartare-Deckert S, Ponzio G, Hofman P, Barbry P, Auberger $\mathrm{P}$, Mari B. Gene expression profiling of normal human pulmonary fibroblasts following coculture with nonsmall-cell lung cancer cells reveals alterations related to matrix degradation, angiogenesis, cell growth and survival. Oncogene. 2003; 22: 8487-97.

17. Zhang D, Wang Y, Shi Z, Liu J, Sun P, Hou X, Zhang J, Zhao S, Zhou BP, Mi J. Metabolic reprogramming of cancerassociated fibroblasts by IDH3 $\alpha$ downregulation. Cell Rep. 2015; 10: 1335-48.

18. Sciamanna I, Vitullo P, Curatolo A, Spadafora C. Retrotransposons, reverse transcriptase and the genesis of new genetic information. Gene. 2009; 448: 180-6.

19. Vogt PK. Retroviral oncogenes: a historical primer. Nat Rev Cancer. 2012; 12: 639-48.

20. Uren AG, Kool J, Berns A, van Lohuizen M. Retroviral insertional mutagenesis: past, present and future. Oncogene. 2005; 24: 7656-72.

21. Touw IP, Erkeland SJ. Retroviral insertion mutagenesis in mice as a comparative oncogenomics tool to identify disease genes in human leukemia. Mol Ther. 2007; 15: 13-9. 
22. Qin ZH, Schuller I, Richter G, Diamantstein T, Blankenstein T. The interleukin-6 gene locus seems to be a preferred target site for retrotransposon integration. Immunogenetics. 1991; 33: $260-6$.

23. Scherz-Shouval R, Santagata S, Mendillo ML, Sholl LM, Ben-Aharon I, Beck AH, Dias-Santagata D, Koeva M, Stemmer SM, Whitesell L, Lindquist S. The reprogramming of tumor stroma by HSF1 is a potent enabler of malignancy. Cell. 2014; 158: 564-78.

24. Augsten M, Hagglof C, Olsson E, Stolz C, Tsagozis P, Levchenko T, Frederick MJ, Borg A, Micke P, Egevad L, Ostman A. CXCL14 is an autocrine growth factor for fibroblasts and acts as a multi-modal stimulator of prostate tumor growth. Proc Natl Acad Sci U S A. 2009; 106: 3414-9.

25. Kiaris H, Chatzistamou I, Trimis G, Frangou-Plemmenou M, Pafiti-Kondi A, Kalofoutis A. Evidence for nonautonomous effect of p53 tumor suppressor in carcinogenesis. Cancer Res. 2005; 65: 1627-30.

26. Lafkas D, Trimis G, Papavassiliou AG, Kiaris H. P53 mutations in stromal fibroblasts sensitize tumors against chemotherapy. Int J Cancer. 2008; 123: 967-71.

27. Grum-Schwensen B, Klingelhofer J, Berg CH, El-Naaman C, Grigorian M, Lukanidin E, Ambartsumian N. Suppression of tumor development and metastasis formation in mice lacking the S100A4 (mts1) gene. Cancer Res. 2005; 65: 3772-80.

28. Yeung TL, Leung CS, Wong KK, Samimi G, Thompson MS, Liu J, Zaid TM, Ghosh S, Birrer MJ, Mok SC. TGF- $\beta$ modulates ovarian cancer invasion by upregulating CAFderived versican in the tumor microenvironment. Cancer Res. 2013; 73: 5016-28.

29. Lili LN, Matyunina LV, Walker L, Benigno BB, McDonald JF. Molecular profiling predicts the existence of two functionally distinct classes of ovarian cancer stroma. Biomed Res Int. 2013; 2013:846387.

30. Sulpice L, Rayar M, Desille M, Turlin B, Fautrel A, Boucher E, Llamas-Gutierrez F, Meunier B, Boudjema K, Clément B. Molecular profiling of stroma identifies osteopontin as an independent predictor of poor prognosis in intrahepatic cholangiocarcinoma. Hepatology. 2013; 58: 1992-2000.

31. Planche A, Bacac M, Provero P, Fusco C, Delorenzi M, Stehle JC, Stamenkovic I. Identification of prognostic molecular features in the reactive stroma of human breast and prostate cancer. PLoS One. 2011; 6: e18640.

32. Sulpice L, Desille M, Turlin B, Fautrel A, Boudjema $\mathrm{K}$, Clement B, Coulouarn C. Gene expression profiling of the tumor microenvironment in human intrahepatic cholangiocarcinoma. Genom Data. 2016; 7: 229-32.

33. Dumas J, Gargano MA, Dancik GM. shinyGEO: a webbased application for analyzing gene expression omnibus datasets. Bioinformatics. 2016; 32:3679-3681.

34. Erck C, Frank R, Wehland J. Tubulin-tyrosine ligase, a longlasting enigma. Neurochem Res. 2000; 25: 5-10.

35. Lafanechère L, Courtay-Cahen C, Kawakami T, Jacrot M, Rudiger M, Wehland J, Job D, Margolis RL. Suppression of tubulin tyrosine ligase during tumor growth. J Cell Sci. 1998; 111: 171-81.

36. Kato C, Miyazaki K, Nakagawa A, Ohira M, Nakamura Y, Ozaki T, Imai T, Nakagawara A. Low expression of human tubulin tyrosine ligase and suppressed tubulin tyrosination/ detyrosination cycle are associated with impaired neuronal differentiation in neuroblastomas with poor prognosis. Int $\mathbf{J}$ Cancer. 2004; 112: 365-75.

37. Mace TA, Ameen Z, Collins A, Wojcik S, Mair M, Young GS, Fuchs JR, Eubank TD, Frankel WL, Bekaii-Saab T, Bloomston M, Lesinski GB. Pancreatic cancer-associated stellate cells promote differentiation of myeloid-derived suppressor cells in a STAT3-dependent manner. Cancer Res. 2013; 73: 3007-18.

38. Bacac M, Provero P, Mayran N, Stehle JC, Fusco C, Stamenkovic I. A mouse stromal response to tumor invasion predicts prostate and breast cancer patient survival. PLoS One. 2006; 1: e32.

39. Tchou J, Kossenkov AV, Chang L, Satija C, Herlyn M, Showe LC, Pure E. Human breast cancer associated fibroblasts exhibit subtype specific gene expression profiles. BMC Med Genomics. 2012; 5: 39.

40. Schmidt M, Schwarzwaelder K, Bartholomae C, Zaoui K, Ball C, Pilz I, Braun S, Glimm H, von Kalle C. Highresolution insertion-site analysis by linear amplificationmediated PCR (LAM-PCR). Nat Methods. 2007; 4: 1051-7.

41. Mialhe A, Lafanechere L, Treilleux I, Peloux N, Dumontet C, Bremond A, Panh MH, Payan R, Wehland J, Margolis $\mathrm{RL}$, Job D. Tubulin detyrosination is a frequent occurrence in breast cancers of poor prognosis. Cancer Res. 2001; 61: 5024-7.

42. Soucek K, Kamaid A, Phung AD, Kubala L, Bulinski JC, Harper RW, Eiserich JP. Normal and prostate cancer cells display distinct molecular profiles of alpha-tubulin posttranslational modifications. Prostate. 2006; 66: 954-65.

43. Whipple RA, Balzer EM, Cho EH, Matrone MA, Yoon JR, Martin SS. Vimentin filaments support extension of tubulinbased microtentacles in detached breast tumor cells. Cancer Res. 2008; 68: 5678-88.

44. Erck C, Peris L, Andrieux A, Meissirel C, Gruber AD, Vernet M, Schweitzer A, Saoudi Y, Pointu H, Bosc C, Salin PA, Job D, Wehland J. A vital role of tubulin-tyrosine-ligase for neuronal organization. Proc Natl Acad Sci U S A. 2005; 102 : 7853-8.

45. Whipple RA, Matrone MA, Cho EH, Balzer EM, Vitolo MI, Yoon JR, Ioffe OB, Tuttle KC, Yang J, Martin SS. Epithelialto-mesenchymal transition promotes tubulin detyrosination and microtentacles that enhance endothelial engagement. Cancer Res. 2010; 70: 8127-37.

46. Cancer Genome Atlas Research N. The Molecular Taxonomy of Primary Prostate Cancer. Cell. 2015; 163: 1011-25.

47. Debidda M, Wang L, Zang H, Poli V, Zheng Y. A role of STAT3 in Rho GTPase-regulated cell migration and proliferation. J Biol Chem. 2005; 280: 17275-85. 
48. Fang J, Yu Z, Lian M, Ma H, Tai J, Zhang L, Han D. Knockdown of zinc finger protein, X-linked (ZFX) inhibits cell proliferation and induces apoptosis in human laryngeal squamous cell carcinoma. Mol Cell Biochem. 2012; 360: 301-7.

49. Han HJ, Russo J, Kohwi Y, Kohwi-Shigematsu T. SATB1 reprogrammes gene expression to promote breast tumour growth and metastasis. Nature. 2008; 452: 187-93.

50. Wu S, Lao XY, Sun TT, Ren LL, Kong X, Wang JL, Wang YC, Du W, Yu YN, Weng YR. Knockdown of ZFX inhibits gastric cancer cell growth in vitro and in vivo via downregulating the ERK-MAPK pathway. Cancer Lett. 2013; 337: 293-300.

51. Zhang Y, Wang Y, Wei Y, Wu J, Zhang P, Shen S, Saiyin H, Wumaier R, Yang X, Wang C. Molecular chaperone CCT3 supports proper mitotic progression and cell proliferation in hepatocellular carcinoma Cells. Cancer Lett. 2016; 372: 101-9.

52. Sherry MM, Reeves A, Wu JK, Cochran BH. STAT3 is required for proliferation and maintenance of multipotency in glioblastoma stem cells. Stem Cells. 2009; 27: 2383-92.

53. Chau CH, Chen KY, Deng HT, Kim KJ, Hosoya KI, Terasaki T, Shih HM, Ann DK. Coordinating Etk/Bmx activation and VEGF upregulation to promote cell survival and proliferation. Oncogene. 2002; 21: 8817-29.

54. Zhao X, Rong L, Zhao X, Li X, Liu X, Deng J, Wu H, Xu X, Erben U, Wu P, Syrbe U, Sieper J, Qin Z. TNF signaling drives myeloid-derived suppressor cell accumulation. J Clin Invest. 2012; 122: 4094-104.

55. Asher AL, Mule JJ, Kasid A, Restifo NP, Salo JC, Reichert CM, Jaffe G, Fendly B, Kriegler M, Rosenberg SA. Murine tumor cells transduced with the gene for tumor necrosis factor-alpha. Evidence for paracrine immune effects of tumor necrosis factor against tumors. J Immunol. 1991; 146: 3227-34.

56. Nanni P, de Giovanni C, Lollini PL, Nicoletti G, Prodi G. TS/A: a new metastasizing cell line from a BALB/c spontaneous mammary adenocarcinoma. Clin Exp Metastasis. 1983; 1: 373-80.

57. Hock H, Dorsch M, Kunzendorf U, Qin Z, Diamantstein T, Blankenstein T. Mechanisms of rejection induced by tumor cell-targeted gene transfer of interleukin 2, interleukin 4, interleukin 7, tumor necrosis factor, or interferon gamma. Proc Natl Acad Sci U S A. 1993; 90: 2774-8.

58. Li LP, Schlag PM, Blankenstein T. Transient expression of SV 40 large $\mathrm{T}$ antigen by Cre/LoxP-mediated site-specific deletion in primary human tumor cells. Hum Gene Ther. 1997; 8: 1695-700.

59. Pear WS, Miller JP, Xu L, Pui JC, Soffer B, Quackenbush RC, Pendergast AM, Bronson R, Aster JC, Scott ML, Baltimore D. Efficient and rapid induction of a chronic myelogenous leukemia-like myeloproliferative disease in mice receiving P210 bcr/abl-transduced bone marrow. Blood. 1998; 92: 3780-92.

60. Westermann J, Aicher A, Qin Z, Cayeux Z, Daemen K, Blankenstein T, Dorken B, Pezzutto A. Retroviral interleukin-7 gene transfer into human dendritic cells enhances T cell activation. Gene Ther. 1998; 5: 264-71.

61. Zhang J, Chen L, Xiao M, Wang C, Qin Z. FSP1+ fibroblasts promote skin carcinogenesis by maintaining MCP-1mediated macrophage infiltration and chronic inflammation. Am J Pathol. 2011; 178: 382-90. 